\title{
REVIEW ARTICLE OPEN Polyacrylamide degradation and its implications in environmental systems
}

\author{
Boya Xiong ${ }^{1}$, Rebeca Dettam Loss ${ }^{2}$, Derrick Shields ${ }^{2}$, Taylor Pawlik ${ }^{2}$, Richard Hochreiter ${ }^{2}$, Andrew L Zydney (D) and Manish Kumar ${ }^{1}{ }^{2}$
}

High molecular weight $\left(10^{6}-3 \times 10^{7} \mathrm{Da}\right)$ polyacrylamide (PAM) is commonly used as a flocculant in water and wastewater treatment, as a soil conditioner, and as a viscosity modifier and friction reducer in both enhanced oil recovery and high volume hydraulic fracturing. These applications of PAM can result in significant environmental challenges, both in water management and in contamination of local water supplies after accidental spills. This paper provides a short review of current applications of high molecular weight PAM, including the potential for PAM degradation by chemical, mechanical, thermal, photolytic, and biological processes. Methods for treating wastewater containing partially degraded PAM are then discussed along with issues related to the potential toxicity and mobility of PAM in the environment after disposal or accidental release.

npj Clean Water (2018)1:17; doi:10.1038/s41545-018-0016-8

\section{INTRODUCTION}

The term "polyacrylamide" is loosely used to describe any polymer with acrylamide present as one of the monomers. ${ }^{1}$ More rigorously, its IUPAC nomenclature is poly (prop-2-enamide), which defines it as a water-soluble polymer formed by the polymerization of either acrylamide monomers or $N, N^{\prime}$-methylenebis(acrylamide). ${ }^{2,3}$ Polyacrylamide with only acrylamide monomers is nonionic; other monomers such as acrylate or 2acrylamido-2-methylpropane sulfonate (AMPS) can be copolymerized at various percentages to form anionic PAM; ${ }^{1,4}$ dimethyldiallylammonium, ethanaminium ( $N, N, N$-trimethyl-2-((1oxo-2-propenyl)oxy), and 1,2-dimethyl-5-vinylpyridinum are common co-monomers for cationic PAM. ${ }^{5}$ Table 1 summarizes the structure and name of commonly used PAM and its co-polymers.

The molecular weight (MW) of commercial PAM ranges from $10^{5}$ to $>10^{7} \mathrm{Da}$. High MW PAM $\left(>10^{6} \mathrm{Da}\right.$ ) has a wider range of applications due to its high viscosity, drag reduction capabilities, and water retention characteristics. ${ }^{6-8}$ PAM is widely used in environmental systems including:

1. as a viscosity enhancer in enhanced oil recovery (EOR) and more recently as a friction reducer in high volume hydraulic fracturing (HVHF) $)^{1,4,9-15}$;

2. as a flocculant in water treatment and sludge dewatering $^{13,16,17}$; and

3. as a soil conditioning agent in agricultural applications ${ }^{18-20}$ and other land management practices.

The applications, properties, specific MWs, and concentration ranges of PAM are summarized in Table 2 . The hydrolyzed form of polyacrylamide (HPAM), a co-polymer of acrylamide and acrylic acid, is the most widely used anionic PAM in oil and gas development as well as in soil conditioning. ${ }^{1,9,12,21}$ The most common commercial PAM formulation in the oil and gas industry is a water-in-oil emulsion, where the polymer is dissolved in the aqueous phase which is encapsulated by a continuous oil phase stabilized by surfactants. ${ }^{1}$

High MW PAM is widely applied in unconventional natural gas development as a "friction reducer" to minimize frictional losses during pumping. ${ }^{4,22-24}$ The drag reduction properties of PAM arise from polymer elongation, which dampens the quasi-streamwise vortices that are characteristic of turbulent flow. ${ }^{25-27}$ The drag reduction properties increase with increasing polymer MW due to the more pronounced stretching of the very long polymer chains. $^{7,28}$ Anionic polyacrylamides perform better as drag reducers in a fresh water environment ${ }^{9}$; cationic PAM has shown enhanced performance at high salinity ${ }^{1}$ due to the reduced electrostatic repulsion from electrolyte shielding present with anionic species. ${ }^{29}$ We reviewed and summarized information from 750 fractured wells across six states from content available on FracFocus.org $^{30}$ (Table S1); 98\% of the wells utilized PAM-based friction reducers with the majority of these using anionic forms of the polymer. It is estimated that fracturing jobs consume $0.2-6$ tons of PAM per well, ${ }^{30}$ corresponding to as much as 75,000 tons of PAM per year in the U.S. alone.

High MW anionic PAM is also the most commonly applied polymer in enhanced oil recovery applications; the use of surfactant-polymer flooding can increase oil recovery by $5-30 \%{ }^{14}$ and in some cases by as much as $80 \% .{ }^{31}$ The surfactant solution increases the mobility of trapped oil by lowering surface tension and increasing rock wettability while the polymer improves oil recovery based on the increased viscosity (5-30 $\left(\mathrm{P}^{32}\right)$. On average, effective polymer flooding requires $0.7-1.75$ tons of polymer per ton of oil extracted ${ }^{14}$ at a concentration of $500-3000 \mathrm{mg} / \mathrm{L}^{32}$. Both HVHF and EOR processes produce a large quantity of wastewater containing residual PAM at a concentration that is as much as half of that in the injected fluid. ${ }^{32}$

Synthetic polymer conditioners like PAM are more effective options than organic or inorganic conditioners in enhancing soil stability, infiltration rate, and erosion resistance. This requires the

\footnotetext{
${ }^{1}$ Department of Civil and Environmental Engineering, The Pennsylvania State University, University Park, Pennsylvania 16802, United States and ${ }^{2}$ Department of Chemical Engineering, The Pennsylvania State University, University Park, Pennsylvania 16802, United States

Correspondence: Andrew L Zydney (zydney@engr.psu.edu) or Manish Kumar (manish.kumar@psu.edu)
}

Received: 21 December 2017 Revised: 18 May 2018 Accepted: 20 May 2018

Published online: 07 September 2018 
Table 1. Chemical structures of PAM and acrylamide co-polymers

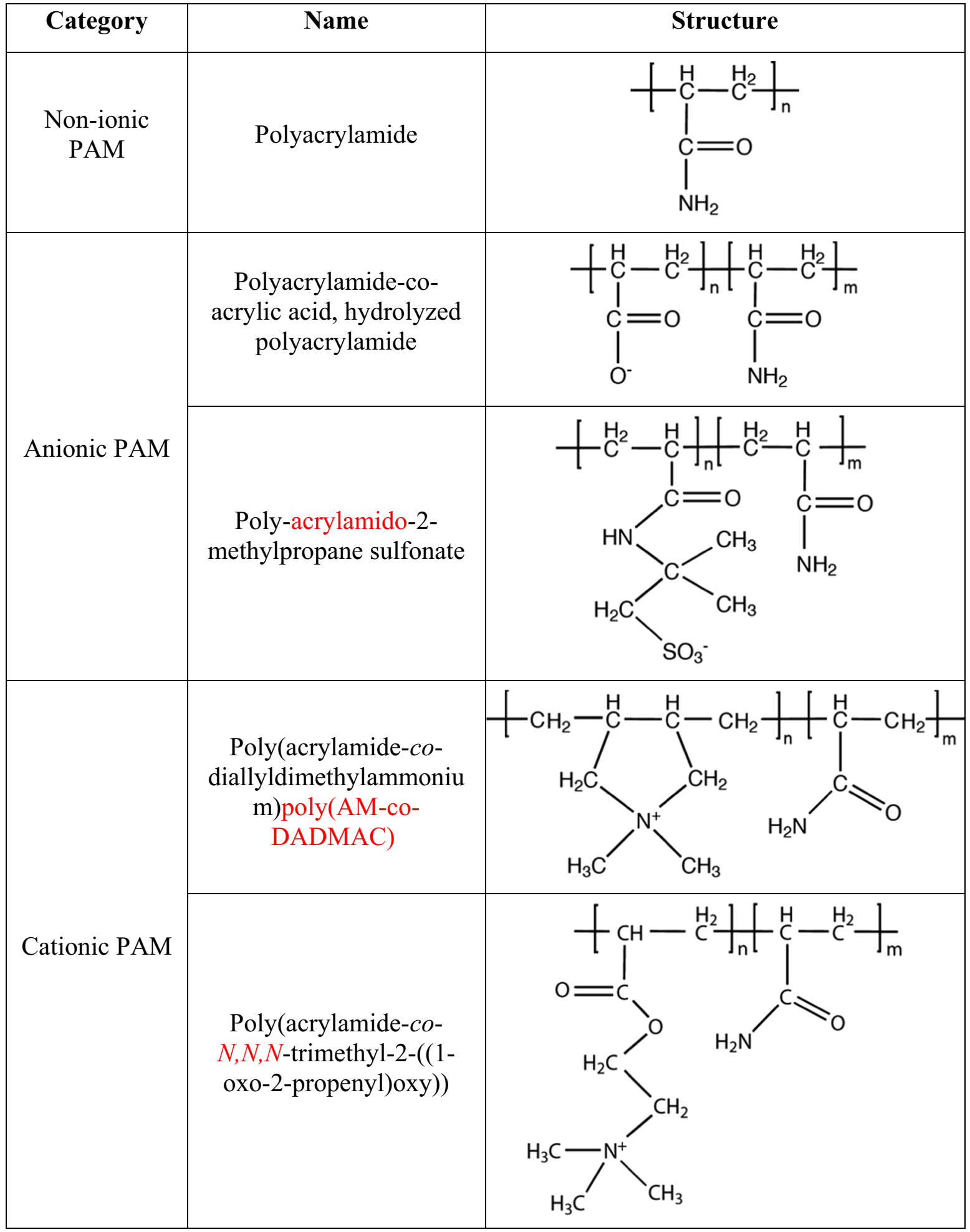

application of $1-20 \mathrm{~kg}$ of polymer per hectare (ha), ${ }^{33,34}$ with typical MW of $1-20 \times 10^{6} \mathrm{Da}^{21,33,35}$ and concentrations less than $10 \mathrm{mg} / \mathrm{L}^{33}$ the high cost of PAM is a significant limitation to more widespread use. PAM is currently used as a soil conditioner on $\sim 800,000 \mathrm{ha}^{33}$ of irrigation land in the U.S., corresponding to
$900-18,000$ tons of PAM per year. PAM binds with soil particles through electrostatic interactions forming aggregates that prevent irrigation-induced erosion and increase the hydraulic conductivity of the soil. Cationic PAM easily adsorbs onto negatively charged clays, while anionic PAM can bridge between clay surfaces via 


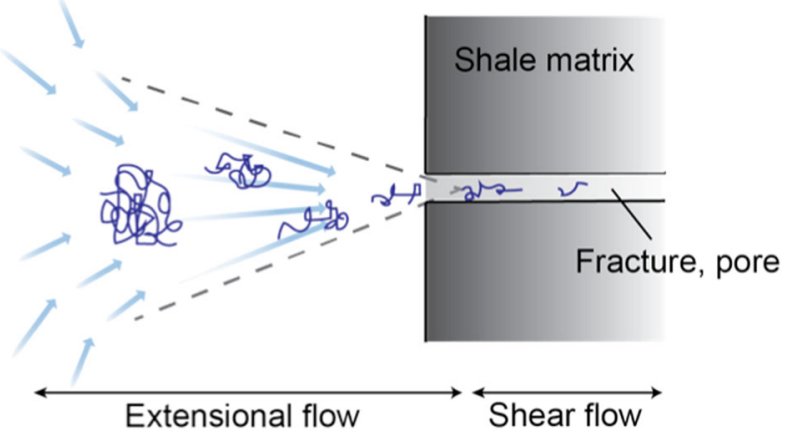

Fig. 1 Mechanical degradation of PAM under extensional flow field through narrow pores and fractures in shale formation

multivalent cations. $^{36}$ Adsorption is enhanced by ion-dipole interactions between the polymer $\mathrm{C}=\mathrm{O}$ groups and clay exchangeable cations and by hydrogen bonding interactions. ${ }^{21}$ Anionic PAM is most commonly used in soil conditioning due to its low mobility in soil and the lower level of residual acrylamide monomer $(<0.05 \%) .21,35$

PAM is also widely used as a flocculant in drinking water treatment (at concentrations $<1 \mathrm{mg} / \mathrm{L}$ ). ${ }^{37}$ PAM can create bridges between destabilized particles, forming micron-size aggregates with good settling properties. ${ }^{38}$ Cationic, nonionic, and anionic PAM have all been studied for flocculation. The flocculation and adsorption capacity increase with increasing $\mathrm{MW}$ due to the greater number of binding sites. ${ }^{13}$ However, polymer molecules with a MW greater than around $18 \times 10^{6} \mathrm{Da}$ are more likely to entangle, reducing interactions with small particles. ${ }^{20}$ High salinity and low $\mathrm{pH}$ suppress electrostatic interactions, while increasing temperature (from 20 to $60^{\circ} \mathrm{C}$ ) enhances the adsorption of anionic PAM to clays due to the reduction in hydrogen bonds between PAM and water ${ }^{17}$ and the increased penetration of PAM into the internal clay structure. ${ }^{16}$

Although the PAM used in environmental systems has a very high MW, it is well known that PAM can undergo degradation by a variety of mechanisms, significantly increasing its mobility and potentially leading to the release of acrylamide monomer, a known toxin and potential carcinogen. This review examines the chemical, mechanical, thermal, photolytic, and biological degradation of PAM under a broad range of environmental conditions. We then consider available options for treating water/wastewater containing PAM, including biodegradation, oxidation, coagulation, and membrane filtration. We also examine the potential for acrylamide release into the environment.

\section{POLYACRYLAMIDE DEGRADATION}

The presence of degraded polyacrylamide could lead to a significant increase in mobility of the molecule in the environment due to the more hydrophilic nature of polyacrylamide with increased content of carboxylic groups after hydrolysis and degradation under various environmental conditions. ${ }^{33,39-42}$ This creates potential challenges for water supplies and wastewater treatment. The general mechanisms of PAM degradation have been reviewed by Caulfield et al. ${ }^{43}$ and are summarized briefly in the following sections.

\section{Degradation mechanisms}

Mechanical degradation is mostly likely to occur in oil and gas processing due to the high shear and elongational rates under turbulent flow through the small pores and fractures within the porous media in these formations as shown schematically in Fig. $1^{44-52}$. Chain rupture typically occurs at the entrance to narrow pores in the sandstone face where the elongational stress is greatest, ${ }^{45,53,54}$ with the polymer chain mostly breaking near the mid-point. 55,56 The pure shear flow through pores or fractures generally causes limited chain scission. ${ }^{57}$ Model experiments showed that polymer degradation in a pure shear flow required more than a 100-fold greater shear rate for equivalent degradation than was observed for flow through a screen mesh where both elongational and shear flows are present. ${ }^{45}$ Thus, limited mechanical degradation is expected during pumping of PAM through chokes, valves, and fractures where flow rates are low; degradation should be higher during flow through near-wellbore areas and perforations where velocities are much higher. ${ }^{58-60}$ Mechanical degradation of PAM is enhanced at high salinity due to changes in polymer rigidity as a result of polymer complexation with ions. ${ }^{61}$

Chemical degradation of PAM that leads to chain scission involves activation of the polymer by free radicals, ${ }^{42,62-66}$ most commonly hydroxyl radicals generated in the environment from the Fenton reaction, 62,65 interactions between oxygen and dissolved $\mathrm{Fe}^{2+41,42,62,67}$ or other transition metals, and sulfate radicals through persulfate activation. ${ }^{66}$ Hydroxyl radials can also be generated from ozone and UV treatment, which will be discussed in the section on photolytic degradation. Free radical induced chain scission has been shown to reduce the MW of PAM from $10^{7}$ to $10^{5} \mathrm{Da}$ within $24 \mathrm{~h}$ upon exposure to iron-bearing shale $\left(1.5 \mathrm{mg} / \mathrm{L} \mathrm{Fe}{ }^{2+}\right)$ at $80^{\circ} \mathrm{C}^{42}$ Incubation of $0.6 \%$ PAM with $30 \mathrm{mM}$ potassium persulfate at $50{ }^{\circ} \mathrm{C}$ caused a $90 \%$ reduction in viscosity in $2 \mathrm{~h}^{68}$ In these studies, free radical chain scission reactions were also found to have a much higher rate under higher temperature conditions. Thermal degradation of polyacrylamide (in the absence of free radicals) does not cause substantial chain scission except at very high temperatures, on the order of $300^{\circ} \mathrm{C}$. Thermal decomposition is a result of inter- or intramolecular imidization of the amide groups, releasing ammonia and forming nitrile groups; as well as the breakage of imide/amide groups and backbone chain scission, generating both nitrogen and carbon dioxide. ${ }^{12,69-71}$ Thermal degradation is unlikely to occur in environmental applications, although temperature does play an important role in determining the rate of chemical and photolytic degradation.

As shown in Equation 1, free radicals attack the polymer backbone via hydrogen abstraction at both the secondary and tertiary carbons, as well as the primary amine, generating polymer radicals $(P)$ as shown in Fig. 2. These polymer radicals react with dissolved oxygen to form polymer peroxyl radicals $\left(\mathrm{PO}_{2}\right)$ at diffusion-controlled rates. Chain scission occurs by a bimolecular reaction between two polymer peroxyl radicals, which then decompose to form polymer fragments $\left(F_{1} \cdot\right.$ and $F_{2}$ in Equations 3 and 4). ${ }^{64}$

$$
\begin{aligned}
& \mathrm{PH}+\mathrm{HO} \rightarrow \mathrm{P}+\mathrm{H}_{2} \mathrm{O} \\
& \mathrm{P}+\mathrm{O}_{2} \rightarrow \mathrm{PO}_{2} \\
& 2 \mathrm{PO}_{2} \rightarrow \mathrm{POOOOP} \rightarrow 2 \mathrm{PO}+\mathrm{O}_{2} \\
& \mathrm{PO} \rightarrow \mathrm{F}_{1}+\mathrm{F}_{2}
\end{aligned}
$$

Many previous studies have demonstrated the importance of dissolved oxygen and $\mathrm{Fe}^{2+}$ in the chemical degradation of PAM<smiles>CC(C)(C)C[C](C(N)=O)C(C)(C)C</smiles><smiles>CC(C)(C)C(C(N)=O)C(C)(C)C</smiles><smiles>CNC(=O)C(CC(C)(C)C)C(C)(C)C</smiles>

Fig. 2 Three possible forms of polymer radicals of polyacrylamide (adapted from ref., ${ }^{64}$ copyright 1982 , with permission from Elsevier) 


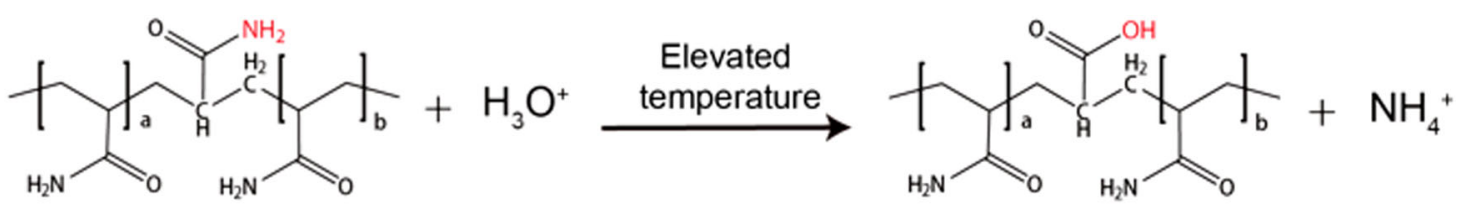

Fig. 3 Hydrolysis of PAM generating a carboxylic acid group and an ammonium ion under acidic conditions

under environmental conditions. ${ }^{40-42,62,64,67,72,73}$ In the absence of dissolved oxygen, polymer viscosity is stable at room temperature, $^{67}$ and may increase slightly due to crosslinking reactions. ${ }^{64}$ $\mathrm{Fe}^{2+}$ can generate hydroxyl radicals by autoxidation under acidic conditions with hydrogen peroxide as an intermediate product. ${ }^{74}$ $\mathrm{Fe}^{2+}$ can be released by oxidative dissolution of pyrite minerals or other iron-bearing clays, which simultaneously acidifies the fluid; this drop in $\mathrm{pH}$ is minimized in the presence of alkaline minerals such as calcite (typical in the Eagle Ford and Antrim shale plays). ${ }^{75}$ Although deep subsurface conditions in EOR or HVHF are anoxic, the injected fluids will carry significant concentrations of oxygen into the formation. This oxygen can cause PAM degradation, although it can also react with pyrite and various hydrocarbons. ${ }^{67,76}$ Oxygen scavengers have been added to EOR fluids to improve fluid stability; ${ }^{41,67}$ this has not been discussed in HVHF applications. In addition, some EOR and HVHF operations utilize persulfate breaker to maximize the fluid return, which will cause accelerated chemical degradation of PAM through the formation of sulfate radicals. ${ }^{66}$

In addition to chain scission, hydrolysis of the amide group leads to the generation of a carboxylic acid group and an ammonium ion (at low pH, see Fig. 3), or the conversion of the acrylamido-2-methylpropane sulfonic acid group (AMPS, Table 1) to a carboxylic acid and an ammonia-2-methyl propanesulfonic acid. ${ }^{77}$ Hydrolysis of nonionic PAM in $0.3 \% \mathrm{NaCl}$ initially causes an increase in viscosity due to the increase in negative charge, with a reduction in viscosity often seen at very high degrees of hydrolysis. $^{78}$ The rate of viscosity decrease during a $24 \mathrm{~h}$ incubation in $1 \mathrm{wt} \% \mathrm{HCl}$ is greatest for PAM, followed by the AMPS co-polymer and then polyDADMAC. ${ }^{29}$ The highly hydrolyzed PAM (>30\% degree of hydrolysis) is prone to precipitation as a result of complexation with divalent cations ${ }^{39,78,79}$ or crosslinking with ferric iron. ${ }^{67}$

Photolytic degradation of PAM in the presence of oxygen is similar to chemical degradation: light exposure generates free radicals (such as hydroxyl radicals) that yield carbon-centered polymer radicals leading to chain scission. ${ }^{43,80,81}$ Equations 5-9 illustrate the pathways of hydroxyl radical generation by photo-activation of catalyst such as $\mathrm{TiO}_{2}, i^{11,82}$ the hydroxyl radicals generated then cause polymer chain scission based on Equations 1-4.

$$
\begin{aligned}
& \text { Catalyst }{ }^{h v} e^{-}+h^{+} \\
& \mathrm{O}_{2}+\mathrm{e}^{-} \rightarrow \mathrm{O}_{2}^{--} \\
& \mathrm{O}_{2}^{--}+\mathrm{H}^{+} \rightarrow \mathrm{HOO} \\
& 2 \mathrm{O}_{2}^{-}+2 \mathrm{H}^{+} \rightarrow \mathrm{H}_{2} \mathrm{O}_{2}+\mathrm{O}_{2} \\
& \mathrm{H}_{2} \mathrm{O}_{2}+\mathrm{O}_{2}^{-} \rightarrow \mathrm{OH}^{-}+\mathrm{OH}^{-}+\mathrm{O}_{2}
\end{aligned}
$$

PAM is exposed to sunlight during soil conditioning, while UV is often used in disinfection of treated water. Model studies show significant photolytic degradation of PAM under illumination by a $125 \mathrm{~W}$ lamp with a photon flux of $5.4 \mu \mathrm{mol} / \mathrm{s}$, reducing the MW from $1.6 \times 10^{5}$ to $7 \times 10^{4} \mathrm{Da}$; no degradation was observed using an $80 \mathrm{~W}$ lamp with photon flux of $3.5 \mu \mathrm{mol} / \mathrm{s}(365 \mathrm{~nm})$ after $3 \mathrm{~h}$. The presence of $\mathrm{TiO}_{2}$ nanoparticles caused a further reduction in MW to $3 \times 10^{4} \mathrm{Da}^{81}$ Photocatalytic degradation is also enhanced in the presence of $\mathrm{Fe}^{3+}$ at low $\mathrm{pH}^{83,84}$ The MW of PAM $(15 \mathrm{mg} / \mathrm{L}$ concentration) was reduced from $2.4 \times 10^{6}$ to $1.2 \times 10^{6}$ Da during $3 \mathrm{~h}$ exposure to simulated sunlight $\left(2 \mathrm{~W} / \mathrm{m}^{2}\right.$ at $\left.300 \mathrm{~nm}\right)$ in the presence of $2 \mathrm{mg} / \mathrm{L}$ ferric ion. ${ }^{85}$

Biodegradation of PAM occurs as microorganisms utilize the amide group of the polymer as a nitrogen source and/or the carbon backbone as a carbon source. ${ }^{19,86}$ The amide group can be hydrolyzed by extracellular amidases, similar to the chemical hydrolysis discussed previously. For example, aliphatic amidase (cd07565) from Pseudomonas putida is expressed upon incubation in the presence of PAM, leading to $46 \%$ degradation of $1000 \mathrm{mg} / \mathrm{L}$ PAM after 7 days at $39^{\circ} \mathrm{C} .{ }^{87}$ Enterobacter aerogenes, Rhodococcus sp., Helicobacter pylori, Bacillus sp., Acinetobacter $s p$. ., Azomonas sp., Pseudomonas sp., Chlostridium sp., and others also express PAM-induced amidases. ${ }^{19,43,88-90}$ It is much harder for microorganisms to utilize the carbon backbone of PAM as a sole carbon source due to the lack of appropriate enzymes. ${ }^{91}$ Wen et al. ${ }^{17}$ have reported that the Bacillus genus can grow on PAM, although the mechanism of backbone chain scission is unclear. Table S2 provides a summary of various bacterial species that are naturally occurring in sludge, soil, and wastewater that are known to degrade PAM. To the best of our knowledge, there have been no reports of detectable residual acrylamide release in aerobic culture media. $^{91-93}$

PAM used as a flocculant in water treatment or sludge dewatering is disposed in high-solid biogas digestors or landfills. ${ }^{94}$ Although PAM is typically considered to be relatively recalcitrant to organic decomposition, ${ }^{95}$ it can be degraded during anaerobic digestion. For example, anaerobes have been shown to hydrolyze PAM complexed with tyrosine-rich proteins. ${ }^{96}$ A recent study found that cationic PAM can be converted to methane via methanogenesis, and it can be depolymerized generating acrylamide and acrylic acid. Acrylamide concentrations as high as $15 \mathrm{mg} / \mathrm{L}$ were identified in a 22-day digestion of sludge containing $12 \mathrm{~g} / \mathrm{kg}$ total suspended solids (equivalent to $240 \mathrm{mg} / \mathrm{L}$ PAM). ${ }^{97}$ Kinetic models of PAM biodegradation under both aerobic and anaerobic conditions have been developed and used to maximize the rate of PAM removal using biological degradation. ${ }^{98}$

Degradation by-products from PAM have not been extensively studied. The mobility of PAM increases as the MW decreases; thus, small chain fragments are likely to be much more mobile than the high MW PAM used in fracking, enhanced oil recovery, and environmental applications. ${ }^{33}$ In addition, hydrolyzed PAM will be more hydrophilic due to the presence of large numbers of carboxylic acid groups.

Acrylamide concentrations in commercial PAM products are typically less than 100-500 parts acrylamide per million repeat units (w/w) as regulated by the Food and Drug Administration (FDA), the U.S. Environmental Protection Agency (EPA), and the National Resources Conservation Services (NRCS).$^{85,99-102}$ During flocculation, conformational changes in the polymer chain can release acrylamide that is initially entrapped within the chain. ${ }^{13,38,100}$ Therefore, PAM used as a flocculant in drinking water treatment is maintained at a concentration $<1 \mathrm{mg} / \mathrm{L}$, ensuring that the concentration of acrylamide monomer in the treated water is less than $0.5 \mathrm{ppb}(\mathrm{w} / \mathrm{v})$. The European Commission (EC) has a stricter limit of $0.1 \mathrm{ppb}(\mathrm{w} / \mathrm{v})$ acrylamide. $^{103}$ The toxicity and environmental fate of acrylamide is discussed in the Outlook section. 
Chain scission of PAM by hydroxyl radicals could lead to the release of acrylamide monomer. Woodrow et al. ${ }^{85}$ detected $3.5 \mathrm{ppb}$ acrylamide $(0.038 \%$ of the monomer units in the initial polymer) after $3 \mathrm{~h}$ exposure to simulated sunlight in the presence of $4.5 \mathrm{mg} / \mathrm{L}$ ferric ion. It was found that PAM solvated with $\mathrm{Fe}^{3+}$ generated ppb levels of acrylamide after exposure to sunlight under acidic conditions ( $\mathrm{pH} \mathrm{6)}$. They concluded that release of acrylamide would be insignificant at low levels of iron $(<0.02 \mathrm{mg} /$ L) under alkaline (7.5-8.5) conditions. Other groups have found that acrylamide can be released from soil conditioners (70 parts per million repeat units) after exposure to natural sunlight over a 2-5 week long period. ${ }^{104,105}$ However, there are still many unresolved questions regarding the release of acrylamide after exposure to UV, with conflicting results reported in the published literature. .8, $85,93,105,106^{-10}$

\section{TREATMENT OF POLYACRYLAMIDE CONTAINING WASTEWATER}

PAM, including degraded PAM molecules, can be present in wastewater generated from oil and gas operations, in runoff from agricultural lands, and in surface waters contaminated by accidental spills or wastewater leakage. While there are no treatment strategies that have been specifically developed for treating PAM/PAM residues, many of the existing water treatment processes should be effective for the removal and/or degradation of PAM.

Coagulation/flocculation utilizes aluminum or iron salts, often in combination with high MW polymers like PAM, to remove organic matter and suspended solids via charge neutralization, adsorption, complexation with metal ions, and sweeping. ${ }^{107,108}$ This process has also been applied for the treatment of oily wastewaters, sometimes in combination with membrane filtration. ${ }^{109-113}$ Zhang et al. ${ }^{98}$ have shown that aluminum sulfate is able to remove $90 \%$ PAM from high salinity oilfield water at $\mathrm{pH} 5$ with a dosage of $80 \mathrm{mg} / \mathrm{L}$. During this process, PAM is removed in flocs and/or sludge, suggesting that coagulation/flocculation can also remove high MW PAM from produced and flowback water. Coagulation is likely to be less effective in removing lower MW degraded PAM, although this has not been studied in any detail. Additional studies are also needed to understand the effects of various produced water constituents on the removal of PAM and degraded PAM by coagulation.

Oxidation of PAM by peroxide, persulfate, ozone, hypochlorite, and permanganate all target the carbon backbone leading to chain scission. ${ }^{65,114-116}$ The resulting polymer fragments are likely to contain ketone, aldehyde, carboxlate, and carbonyl groups. ${ }^{117}$ Persulfate is the most commonly used oxidant in oilfield operations, reducing the viscosity and improving oil recovery. ${ }^{68,118}$ Persulfate can effectively degrade PAM at $82^{\circ} \mathrm{C}$ after only $1 \mathrm{~h}$ at concentrations as low as $5 \mathrm{ppt}^{66}$ leading to more than a $50 \%$ reduction in viscosity. High temperatures and persulfate concentrations both increase the rate of polymer degradation by increasing the concentration of sulfate radicals.

Fenton reactions are widely used in advanced oxidation processes to decompose hydrocarbons, ${ }^{65}$ natural organic matter, $^{119}$ and emerging contaminants. ${ }^{120}$ In the Fenton reaction, hydroxyl radicals $(\mathrm{OH})$ are generated via reaction between ferrous iron and hydrogen peroxide. ${ }^{62-64,121}$ The hydroxyl radicals generated via the Fenton reaction can degrade more than $90 \%$ of PAM with initial MW of $5.2 \times 10^{6} \mathrm{Da}$ at a concentration of $5000 \mathrm{mg} / \mathrm{L}^{62}$ Ramsden and McKay observed a $54 \%$ reduction of the initial MW after $1 \mathrm{~h}$ incubation of PAM with $1 \mathrm{mg} / \mathrm{L} \mathrm{of} \mathrm{Fe}^{2+}$ and $\mathrm{H}_{2} \mathrm{O}_{2}$; increasing the $\mathrm{Fe}^{2+}$ concentration to $50 \mathrm{mg} / \mathrm{L}$ caused a $93 \%$ reduction in MW. ${ }^{62}$ Studies of PAM degradation by the Fenton reaction alone did not detect any acrylamide monomer, ${ }^{62}$ although there is evidence for acrylamide release from combined UV/Fenton reactions. ${ }^{65}$
Ozone is widely used as a disinfectant in water treatment. ${ }^{122}$ The ozone molecule is extremely unstable in the presence of UV, releasing oxygen and forming hydrogen peroxide after reaction with water. ${ }^{123}$ Ozone degrades PAM via free radical induced chain scission as described previously. ${ }^{123}$ Ozonation at a concentration of $3.0 \mathrm{mg} / \mathrm{L}(\mathrm{w} / \mathrm{v})$ leads to an $80 \%$ reduction in the MW of PAM within $15 \mathrm{~min}$ at $\mathrm{pH}$ 3. Suziki et al. ${ }^{117}$ also demonstrated that acrylamide monomer could be almost completely degraded after $30 \mathrm{~min}$ of exposure to ozone at $\mathrm{pH} 6$.

Chlorine is the most widely used disinfectant in drinking water treatment. Chlorination was found to reduce the MW of nonionic PAM by $19 \%$ after $10 \mathrm{~min}$ at a chlorine concentration of $20 \mathrm{mg} /$ $\mathrm{L}^{114}$. In contrast, anionic PAM was largely unaffected by chlorine. ${ }^{116}$ Gas chromatography (GC) coupled with an electron capture detector (ECD) has shown that chlorination does not cause the release of acrylamide. The double bond in the acrylamide monomer present in the original polymer solution can react with chlorine to form - $\mathrm{ClC}-\mathrm{COH}^{-14,116,124}$ and possibly chloroform, which is a health concern at concentrations $>50 \mathrm{mg} /$ $\mathrm{L}^{125}$. Solution $\mathrm{pH}$ dictates the speciation of chlorine with the highest removal of acrylamide observed at $\mathrm{pH} 6$ and 10 when hypochlorous acid $(\mathrm{HOCl})$ and hypochlorite $\left(\mathrm{OCl}^{-}\right)$are the dominant species, respectively. ${ }^{126}$

Biological treatment in the form of membrane bioreactors, ${ }^{127,128}$ biologically active filtration, ${ }^{129}$ or conventional activated sludge ${ }^{19,130}$ can effectively remove more than $90 \%$ of the organic matter in wastewater. However, relatively little is known about the effectiveness of these processes at removing PAM. Bao et al. ${ }^{127}$ found that a membrane bioreactor removed no more than $40 \%$ of PAM after 7 days. ${ }^{127}$ Previous studies suggest that Bacillus flexus can remove more than $75 \%$ of a $10^{7}$ Da PAM at $60 \mathrm{mg} / \mathrm{L}$ after incubation for $96 \mathrm{~h},{ }^{19}$ although only $20 \%$ removal was achieved in the first $24 \mathrm{~h}$. Additional work will be needed to optimize the design of biological systems for the effective degradation of PAM.

Membrane processes such as microfiltration (MF) and ultrafiltration (UF) are commonly used in oilfield wastewater treatment to remove suspended solids, oilfield chemicals, and residual oil. ${ }^{131}$ Nanofiltration (NF), reverse osmosis (RO), ${ }^{132}$ forward osmosis (FO), ${ }^{133}$ and membrane distillation (MD) ${ }^{134}$ have all been examined for the removal of monovalent and divalent salts. ${ }^{135}$ Membrane processes coupled with coagulation, acid hydrolysis, and biological processes have been shown to remove up to $95 \%$ of the residual PAM from oily wastewater. ${ }^{110}$ UF membranes can potentially remove lower MW PAM from HVHF wastewaters, while even smaller PAM fragments $\left(<10^{3} \mathrm{Da}\right)$ can be removed by NF and RO. Acrylamide monomer $(71 \mathrm{Da})$ is likely to be only partially removed by $\mathrm{RO}$, although high rates of removal should be possible using activated carbon and advanced oxidation.

The biggest challenge in applying membrane processes to produced waters generated from oil and gas processing is membrane fouling caused by the high concentrations and wide range of constituents present in these wastewaters. ${ }^{109,136,137}$ HPAM was found to be the dominant membrane foulant in EOR wastewater, responsible for $80 \%$ of the fouling followed by oil and suspended solids. ${ }^{138}$ PAM rejection and fouling is typically increased at high salinity due to compaction of PAM on the membrane surface. ${ }^{139,140}$ High $\mathrm{pH}$ leads to the formation of molecular complexes and a corresponding increase in fouling. ${ }^{141,142}$ High polymer concentrations can be particularly problematic due to the formation of entanglements and micelles (at PAM concentrations above the critical micelle concentration or CMC). ${ }^{139}$ Furthermore, residual PAM in EOR wastewater ${ }^{110}$ was found to stabilize oil-water emulsions, leading to increased fouling. ${ }^{143,144}$ Pretreatment strategies that remove PAM are likely to mitigate the degree of fouling during subsequent membrane processes. Future work is needed to identify optimal cleaning strategies for membranes fouled by PAM. 


\section{OUTLOOK}

High MW PAM and its co-polymers are used extensively in oil and gas processing, water treatment, and agricultural applications. Oil and gas processes utilize PAM at much higher concentrations (500-3000 mg/L) than in water treatment and soil management $(<10 \mathrm{mg} / \mathrm{L})$. In addition, the former applications also impose a much higher mechanical stress and much harsher chemical/ thermal conditions, both of which can lead to significant chemical and mechanical degradation of the PAM. In contrast, the very long time exposure of PAM in agricultural (and landfill) applications increases the likelihood and degree of both photolytic and biological degradation.

Although much is known about the factors controlling the rate and extent of PAM degradation, there are still significant unanswered questions, particularly in emerging applications like high volume hydraulic fracturing (HVHF). A significant level of mechanical degradation of PAM is inevitable in HVHF applications due to the high flow rates, pressures, and elongational stresses during fracturing operations. However, the magnitude of the shear and elongational stresses in different shale plays and under different fracturing conditions needs to be quantified, e.g., through the use of core-flooding tests on different shale samples. Several methods have been proposed for enhancing fluid stability by reducing PAM degradation in EOR applications, such as the utilization of oxygen scavengers and reducing agents, replacement of alloys in surface facilities to reduce iron dissolution, and selection/design of proper chokes and pumps; ${ }^{32}$ additional work will be required to determine how to most effectively apply these approaches in HVHF operations.

Degraded PAM can be discharged to the environment directly from agricultural runoff and in the discharge from water treatment facilities, both of which will be at very low concentrations $(<\mathrm{ppm})$. In contrast, wastewaters generated from oilfields and fracturing sites contain a high concentration of PAM residues $(10-1000 \mathrm{mg} /$ L) that can be released via accidental spill and leakage. However, relatively little information is currently available regarding the detailed chemical characteristics of the degraded products produced by mechanical, chemical, and photolytic degradation of PAM. Analytical methods such as gel permeation chromatography (GPC) and viscosity measurements are most widely employed to quantify PAM degradation. Fourier transform infrared spectroscopy (FTIR) and Nuclear magnetic resonance (NMR) have been used to identify specific functional groups; ketone, aldehyde, and carboxylic groups have all been reported in chemically, photolytically, and thermally degraded PAM. To the best of our knowledge, mechanically degraded PAM has not been chemically analyzed. Future studies using liquid/GC coupled with mass spectrometry could provide a more comprehensive analysis of the products present in degraded PAM under a variety of conditions. Moreover, the toxicity, transport, fate, and removal efficiency of degraded PAM needs to be re-examined in light of existing information on both PAM and the acrylamide monomer. The mobility of PAM in natural environments is limited due to its high MW and adsorption onto mineral surfaces. PAM is highly retained in porous media, such as soil, and it easily settles in waterbeds. ${ }^{100,145}$ PAM is also too large to penetrate biological cell membranes. ${ }^{146}$ However, smaller PAM with different functional groups could behave very differently.

Although PAM is relatively nontoxic to humans, animals, fish, or plants, 6,33,65,147 the acrylamide monomer can be adsorbed via dermal exposure and inhalation, and it is a known neurotoxin and a potential carcinogen ${ }^{148}$ : it is immediately dangerous at concentrations of $0.06 \mathrm{mg} / \mathrm{L}$ and is lethal (LD50) at $150-200 \mathrm{mg} /$ $\mathrm{kg}$ body weight. ${ }^{149-151}$ A 13-week exposure to acrylamide in drinking water at a concentration above $1 \mathrm{mg} / \mathrm{kg} /$ day leads to peripheral nerve alterations as observed under electron microscopy. Acrylamide at a dose of $20 \mathrm{mg} / \mathrm{kg} /$ day stimulated the degeneration of peripheral nerves and the spinal cord of rats, although no obvious effects were found at doses less than $0.2 \mathrm{mg} /$ $\mathrm{kg} /$ day. ${ }^{152}$ Acrylamide is highly soluble in water (log $K_{\text {ow }}=$ $-0.67)^{153}$ and is therefore highly mobile in the environment. Several studies support the hypothesis that naturally occurring microbes in soils, sediments, and water systems can degrade acrylamide to the nontoxic products ammonia and acrylic acid over periods of days to months. ${ }^{92,93,104,145,154,155}$ For example, Shanker et al. ${ }^{92}$ observed the complete disappearance of $500 \mathrm{mg} /$ $\mathrm{L}$ of acrylamide ( $\mathrm{w} / \mathrm{w}$ of soil) within 5 days under aerobic conditions at $30^{\circ} \mathrm{C}$. In aquatic systems, complete degradation of acrylamide likely occurs within 2 weeks. ${ }^{92,156,157}$ However, in tap water, acrylamide can persist for more than 2 months. ${ }^{158}$ Even if acrylamide is readily biodegradable in the environment, careful monitoring should be implemented to ensure that there are no dangerous releases of acrylamide from various applications.

The complexity of the produced and flowback waters generated in oil and gas processing creates major challenges for wastewater treatment; current industry practice makes extensive use of permanent storage in tanks or injection wells at a cost of $\sim 0.03$ $\$ / L{ }^{159}$ The substantial demand for water to fracture wells has also led to the reuse of flowback water in subsequent fracking operations. Residual PAM has not been identified as a significant challenge for reuse, although the degraded polymer could lead to plugging of small fractures and formation pores which would reduce gas and oil permeability. ${ }^{160-162} \mathrm{~A}$ variety of treatment technologies are potentially available for removal/degradation of PAM, although the performance of these systems has yet to be evaluated, particularly for PAM fragments. Previous studies have shown high rates of PAM degradation by oxidation. ${ }^{65,163}$ Dai et al. showed that a hybrid treatment process combining hydrolysiscoagulation with a membrane bioreactor could reduce PAM concentrations by more than $95 \% .{ }^{96}$ It may also be possible to use chemical oxidation, such as the Fenton reaction, combined with coagulation. Membrane processes such as RO can provide treated water with a low TDS and TOC, although pretreatment costs, including those associated with the removal of PAM, are likely to be high. Detailed cost analyses will need to be performed to determine the most effective strategies for water treatment in these diverse applications, taking into account the nature of the feed and the concentration/properties of the degraded polyacrylamide.

\section{ACKNOWLEDGEMENTS}

Partial support for this work was provided by a Penn State College of Engineering Innovation Grant and a seed grant through the Center for Collaborative Research in Intelligent Gas Systems (CCRINGS) program funded by General Electric (GE). Additional support was provided by the Pennsylvania Water Resources Research Center small grants program.

\section{AUTHOR CONTRIBUTIONS}

B.X., R.D.L., D.S., R.H., and T.P. performed the literature survey and prepared an initial draft of the manuscript. A.L.Z. and M.K. supervised the work and provided extensive contributions to the preparation of the final version of the manuscript.

\section{ADDITIONAL INFORMATION}

Supplementary information accompanies the paper on the npj Clean Water website (https://doi.org/10.1038/s41545-018-0016-8).

Competing interests: The authors declare no competing interests.

Publisher's note: Springer Nature remains neutral with regard to jurisdictional claims in published maps and institutional affiliations. 


\section{REFERENCES}

1. Paktinat, J., O'Neil, B. J., Aften, C. W. \& Hurd, M. D. Critical evaluation of high brine tolerant additives used in shale slickwater fracs. In SPE Production and Operations Symposium. (Society of Petroleum Engineers, Richardson, TX, 2011).

2. Raymond, S., \& Weintraub, L. Acrylamide gel as a supporting medium for zone electrophoresis. Science 130, 711-711 (1959).

3. Andersen, F. A. Amended final report on the safety assessment of polyacrylamide and acrylamide residues in cosmetics. Int. J. Toxicol. 24, 21-50 (2005).

4. Sun, H., Stevens, R. F., Cutler, J. L., Wood, B., Wheeler, R. S. and Qu, Q. A novel nondamaging friction reducer: development and successful slickwater frac applications. In Tight Gas Completions Conference. (Society of Petroleum Engineers, Richardson, TX, 2010).

5. Rabiee, A., Ershad-Langroudi, A. \& Zeynali, M. E. A survey on cationic polyelectrolytes and their applications: acrylamide derivatives. Rev. Chem. Eng. 31, 239-261 (2015).

6. Seybold, C. Polyacrylamide review: soil conditioning and environmental fate. Commun. Soil Sci. Plant Anal. 25, 2171-2185 (1994).

7. Virk, P. S. Drag reduction fundamentals. AlChE J. 21, 625-656 (1975).

8. Tolstikh, L., Akimov, N., Golubeva, I. \& Shvetsov, I. Degradation and stabilization of polyacrylamide in polymer flooding conditions. Int. J. Polym. Mater. 17, 177-193 (1992).

9. Rodvelt, G., Yuyi, S. \& VanGilder, C. Use of a salt-tolerant friction reducer improves production in Utica completions. In SPE Eastern Regional Meeting. (Society of Petroleum Engineers, Richardson, TX, 2015).

10. $\mathrm{Xu}, \mathrm{L}$. L., Case study: a new salt-tolerant friction reducer system enables $100 \%$ reuse of produced water in the Marcellus shale. In SPE Eastern Regional Meeting. (Society of Petroleum Engineers, Richardson, TX, 2016).

11. Zelenev, A. S., Gilzow, G. A. \& Kaufman, P. B. Fast inverting, brine and additive tolerant friction reducer for well stimulation. In SPE International Symposium on Oilfield Chemistry. (Society of Petroleum Engineers, Richardson, TX, 2009).

12. Swiecinski, F., Reed, P. \& Andrews, W. The thermal stability of polyacrylamides in EOR applications. In SPE Improved Oil Recovery Conference. (Society of Petroleum Engineers, Richardson, TX, 2016).

13. Guezennec, A. G. M., et al. Transfer and degradation of polyacrylamide-based flocculants in hydrosystems: a review. Environ. Sci. Pollut. Res. Int. 22, 6390-6406 (2015).

14. Abidin, A., Puspasari, T. \& Nugroho, W. Polymers for enhanced oil recovery technology. Procedia Chem. 4, 11-16 (2012).

15. Sabhapondit, A., Borthakur, A. \& Haque, I. Characterization of acrylamide polymers for enhanced oil recovery. J. Appl. Polym. Sci. 87, 1869-1878 (2003).

16. Tekin, N., Demirbaş, Ö., \& Alkan, M. Adsorption of cationic polyacrylamide onto kaolinite. Microporous Mesoporous Mater. 85, 340-350 (2005).

17. Mpofu, P., Addai-Mensah, J. \& Ralston, J. Temperature influence of nonionic polyethylene oxide and anionic polyacrylamide on flocculation and dewatering behavior of kaolinite dispersions. J. Colloid Interface Sci. 271, 145-156 (2004).

18. Castle, L. Determination of acrylamide monomer in mushrooms grown on polyacrylamide gel. J. Agric. Food Chem. 41, 1261-1263 (1993).

19. Wen, Q., Chen, Z., Zhao, Y., Zhang, H. \& Feng, Y. Biodegradation of polyacrylamide by bacteria isolated from activated sludge and oil-contaminated soil. J. Hazard Mater. 175, 955-959 (2010).

20. Lee, B. \& Schlautman, M. Effects of polymer molecular weight on adsorption and flocculation in aqueous kaolinite suspensions dosed with nonionic polyacrylamides. Water 7, 5896-5909 (2015).

21. Levy, G. J. \& Warrington, D. N. Polyacrylamide addition to soils: impacts on soil structure and stability. in Functional Polymers in Food Science: From Technology to Biology (eds. Cirillo, G., Spizzirri, U. G., lemma, F.). Ch. 2 (Scrivener, Salem, MA, 2015)

22. Aften, C. \& Watson, W. P. Improved friction reducer for hydraulic fracturing. (Society of Petroleum Engineers, Richardson, TX, 2009).

23. Fink, J. Hydraulic Fracturing Chemicals and Fluids Technology. (Gulf Professional Publishing, Houston, TX, 2013).

24. Al-Sarkhi, A. Drag reduction with polymers in gas-liquid/liquid-liquid flows in pipes: A literature review. J. Nat. Gas. Sci. Eng. 2, 41-48 (2010).

25. Dubief, Y. et al. New answers on the interaction between polymers and vortices in turbulent flows. Flow. Turbul. Combust. 74, 311-329 (2005).

26. Usui, H., Kodama, M. \& Sano, Y. Laser-Doppler measurements of turbulence structure in a drag-reducing pipe flow with polymer injection. J. Chem. Eng. Jpn. 21, 134-140 (1988).

27. White, C. M. \& Mungal, M. G. Mechanics and prediction of turbulent drag reduction with polymer additives. Annu. Rev. Fluid Mech. 40, 235-256 (2008).

28. Lumley, J. L. Drag reduction by additives. Annu. Rev. Fluid Mech. 1, 367-384 (1969).

29. Pei, Y., et al. Investigation of the degradation and stability of acrylamide-based polymers in acid solution: Functional monomer modified polyacrylamide. Petroleum 2, 399-407 (2016).
30. FracFocus Chemical Disclosure Registry. What Chemicals Are Used, https:// fracfocus.org/chemical-use/what-chemicals-are-used (2017). Last accessed 30 Apr 2018.

31. Baviere, M., Glenat, P., Plazanet, V. \& Labrid, J. Improvement of the efficiency/ cost ratio of chemical EOR processes by using surfactants, polymers, and alkalis in combination. SPE Reserv. Eng. 10, 187-193 (1995).

32. Thomas, A., Gaillard, N. \& Favero, C. Some key features to consider when studying acrylamide-based polymers for chemical enhanced oil recovery. Oil Gas Sci. Technol. 67, 887-902 (2012).

33. Sojka, R. E., Bjorneberg, D. L., Entry, J. A., Lentz, R. D. \& Orts, W. J. Polyacrylamide in agriculture and environmental land management. Adv. Agron. 92, 75-162 (2007).

34. Smith, H., Levy, G. \& Shainberg, I. Water-droplet energy and soil amendments: effect on infiltration and erosion. Soil Sci. Soc. Am. J. 54, 1084-1087 (1990).

35. Barvenik, F. W. Polyacrylamide characteristics related to soil applications. Soil Sci. 158, 235-24 (1994).

36. Laird, D. A. Bonding between polyacrylamide and clay mineral surfaces. Soil Sci. 162, 826-832 (1997).

37. Wong, S., Teng, T., Ahmad, A., Zuhairi, A. \& Najafpour, G. Treatment of pulp and paper mill wastewater by polyacrylamide (PAM) in polymer induced flocculation. J. Hazard Mater. 135, 378-388 (2006).

38. Aguilar, M. I. et al. Improvement of coagulation-flocculation process using anionic polyacrylamide as coagulant aid. Chemosphere 58, 47-56 (2005).

39. Muller, G., Fenyo, J. C. \& Selegny, E. High molecular weight hydrolyzed polyacrylamides. III. Eff. Temp. Chem. Stab. J. Appl. Polym. Sci. 25, 627-633 (1980).

40. Muller, $\mathrm{G}$. Thermal stability of high-molecular-weight polyacrylamide aqueous solutions. Polym. Bull. 5, 31-37 (1981).

41. Shupe, R. D. Chemical stability of polyacrylamide polymers. J. Pet. Technol. 33, 1513-1529 (1981).

42. Xiong, B. et al. Chemical degradation of polyacrylamide during hydraulic fracturing. Environ. Sci. Technol. 52, 327-336 (2018).

43. Caulfield, M. J., Qiao, G. G. \& Solomon, D. H. Some aspects of the properties and degradation of polyacrylamides. Chem. Rev. 102, 3067-3084 (2002).

44. Martin, F. Mechanical degradation of polyacrylamide solutions in core plugs from several carbonate reservoirs. SPE Form. Eval. 1, 139-150 (1986).

45. Maerker, J. M. Shear degradation of partially hydrolyzed polyacrylamide solutions. Soc. Petrol. Eng. J. 15, 311-322 (1975).

46. Zhang, K., Lim, G. H. \& Choi, H. J. Mechanical degradation of water-soluble acrylamide copolymer under a turbulent flow: effect of molecular weight and temperature. J. Ind. Eng. Chem. 33, 156-161 (2016).

47. Brakstad, K. \& Rosenkilde, C. Modelling viscosity and mechanical degradation of polyacrylamide solutions in porous media. In SPE Improved Oil Recovery Conference. (Society of Petroleum Engineers, Richardson, TX, 2016).

48. Jouenne, S., Chakibi, H. \& Levitt, D. Polymer stability after successive mechanicaldegradation events. Soc. Petrol. Eng. J. 23, 18-33 (2018).

49. Bueche, F. Mechanical degradation of high polymers. J. Appl. Polym. Sci. 4, 101-106 (1960).

50. Culter, J. D., Zakin, J. L. \& Patterson, G. K. Mechanical degradation of dilute solutions of high polymers in capillary tube flow. J. Appl. Polym. Sci. 19, 3235-3240 (1975).

51. Noik, C., Delaplace, P. \& Muller, G. Physico-chemical characteristics of polyacrylamide solutions after mechanical degradation through a porous medium. In SPE International Symposium on Oilfield Chemistry. (Society of Petroleum Engineers, Richardson, TX, 1995).

52. Vanapalli, S. A., Ceccio, S. L., \& Solomon, M. J. Universal scaling for polymer chain scission in turbulence. Proc. Natl. Acad. Sci. USA 103, 16660-16665 (2006).

53. Ghoniem, S., Chauveteau, G., Moan, M. \& Wolff, C. Mechanical degradation of semidilute polymer solutions in laminar flows. Can. J. Chem. Eng. 59, 450-454 (1981).

54. Seright, R. The effects of mechanical degradation and viscoelastic behavior on injectivity of polyacrylamide solutions. Soc. Petrol. Eng. J. 23, 475-485 (1983).

55. Keller, A., \& Odell, J. The extensibility of macromolecules in solution: a new focus for macromolecular science. Colloid Polym. Sci. 263, 181-201 (1985).

56. Perkins, T. T., Smith, D. E. \& Chu, S. Single polymer dynamics in an elongational flow. Science 276, 2016-2021 (1997).

57. Al Hashmi, A. R. et al. Rheology and mechanical degradation of high-molecularweight partially hydrolyzed polyacrylamide during flow through capillaries. J. Pet. Sci. Technol. Eng. 105, 100-106 (2013).

58. Gumpenberger, T., Deckers, M., Kornberger, M. \& Clemens, T. Experiments and simulation of the near-wellbore dynamics and displacement efficiencies of polymer injection, Matzen Field, Austria. In Abu Dhabi International Petroleum Conference and Exhibition. (Society of Petroleum Engineers, Richardson, TX, 2012).

59. Puls, C., Clemens, T., Sledz, C., Kadnar, R. \& Gumpenberger, T. Mechanical degradation of polymers during injection, reservoir propagation and production - field test results 8th reservoir, Austria. In SPE Europec featured at 78th EAGE Conference and Exhibition, Vienna, Austria. (Society of Petroleum Engineers, Richardson, TX, 2016). 
60. Echner, M., et al. Flow of polyacrylamide polymers in the near-wellbore-region, rheological behavior within induced fractures and near-wellbore-area. In SPE Annual Technical Conference and Exhibition. (Society of Petroleum Engineers, Richardson, TX, 2013).

61. Karami, H. R., Rahimi, M. \& Ovaysi, S. Degradation of drag reducing polymers in aqueous solutions. Korean J. Chem. Eng. 35, 1-10 (2018).

62. Ramsden, D. K. \& McKay, K. Degradation of polyacrylamide in aqueous solution induced by chemically generated hydroxyl radicals: Part I-Fenton's reagent. Polym. Degrad. Stab. 14, 217-229 (1986).

63. Ramsden, D. K., \& McKay, K. The degradation of polyacrylamide in aqueous solution induced by chemically generated hydroxyl radicals: Part II-Autoxidation of $\mathrm{Fe}^{2+}$. Polym. Degrad. Stab 15, 15-31 (1986).

64. Grollmann, U., \& Schnabel, W. Free radical-induced oxidative degradation of polyacrylamide in aqueous solution. Polym. Degrad. Stab 4, 203-212 (1982).

65. Lu, M., Wu, X. \& Wei, X. Chemical degradation of polyacrylamide by advanced oxidation processes. Environ. Technol. 33, 1021-1028 (2012).

66. Carman, P. S., Cawiezel, K. E. \& Co, B. J. S. Successful breaker optimization for polyacrylamide friction reducers used in slickwater fracturing. In SPE Hydraulic Fracturing Technology Conference. (Society of Petroleum Engineers, Richardson, TX, 2007).

67. Seright, R. \& Skjevrak, I. Effect of dissolved iron and oxygen on stability of hydrolyzed polyacrylamide polymers. Soc. Petrol. Eng. J. 20, 433-441 (2015).

68. Gao, J. et al. Accelerate chemical degradation of polyacrylamide. Macromol. Symp. 144, 179-185 (1999).

69. Leung, W., Axelson, D. \& Van Dyke, J. Thermal degradation of polyacrylamide and poly (acrylamide - co - acrylate). J. Polym. Sci. A: Polym. Chem. 25, 1825-1846 (1987).

70. Al-Muntasheri, G. A., Nasr-El-Din, H. A., Peters, J. A. \& Zitha, P. L. Thermal decomposition and hydrolysis of polyacrylamide-co-tert-butyl acrylate. Eur. Polym. J. 44, 1225-1237 (2008).

71. Kitahara, Y. et al. Thermal decomposition of acrylamide from polyacrylamide: time-resolved pyrolysis with ion-attachment mass spectrometry. J. Therm. Anal. Calorim. 110, 423-429 (2012).

72. Cannella, W., Huh, C. \& Seright, R. Prediction of xanthan rheology in porous media. In SPE Annual Technical Conference and Exhibition. (Society of Petroleum Engineers, Richardson, TX, 1988).

73. Jouenne, S., Klimenko, A. \& Levitt, D. Polymer flooding: establishing specifications for dissolved oxygen and iron in injection water. Soc. Petrol. Eng. J. 22, 438-446 (2017).

74. Kosaka, H., Katsuki, Y., \& Shiga, T. Spin trapping study on the kinetics of $\mathrm{Fe}^{2+}$. autoxidation: formation of spin adducts and their destruction by superoxide. Arch. Biochem. Biophys. 293, 401-408 (1992).

75. Chermak, J. A. \& Schreiber, M. E. Mineralogy and trace element geochemistry of gas shales in the United States: Environmental implications. Int. J. Coal Geol. 126, 32-44 (2014).

76. Harrison, A. L. et al. Element release and reaction-induced porosity alteration during shale-hydraulic fracturing fluid interactions. Appl. Geochem. 82, 47-62 (2017).

77. Sandengen, K., Widerøe, H., Nurmi, L. \& Hanski, S. Hydrolysis kinetics of ATBS polymers at elevated temperature, via 13C NMR spectroscopy, as basis for accelerated aging tests. J. Pet. Sci. Technol. Eng. 158, 680-692 (2017).

78. Seright, R. S., Campbell, A., Mozley, P. \& Han, P. Stability of partially hydrolyzed polyacrylamides at elevated temperatures in the absence of divalent cations. Soc. Petrol. Eng. J. 15, 341-348 (2010).

79. Stahl, G., Moradi-Araghi, A. \& Doe, P. in Water-Soluble Polymers for Petroleum Recovery (eds. Stahl, G. A., Schulz, D. N.) Ch. 6 (Springer, Berlin, 1988).

80. Schnabel, W. Oxidative degradation processes in synthetic and biological polymers as studied by pulse radiolysis experiments. J. Radioanal. Nucl. Chem. 101, 413-432 (1986).

81. Vijayalakshmi, S. P. \& Madras, G. Photocatalytic degradation of poly(ethylene oxide) and polyacrylamide. J. Appl. Polym. Sci. 100, 3997-4003 (2006).

82. Bauer, C., Jacques, P., \& Kalt, A. Photooxidation of an azo dye induced by visible light incident on the surface of $\mathrm{TiO}_{2}$. J. Photopolym. Sci. Technol. A: Chem. 140, 87-92 (2001).

83. Larson, R. A., Schlauch, M. B. \& Marley, K. A. Ferric ion promoted photodecomposition of triazines. J. Agric. Food Chem. 39, 2057-2062 (1991).

84. Langford, C. H., \& Carey, J. H. The charge transfer photochemistry of the Hexaaquoiron (III) ion, the Chloropentaaquoiron (III) ion, and the $\mu$-Dihydroxo dimer explored with tert-butyl alcohol scavenging. Can. J. Chem. 53, 2430-2435 (1975).

85. Woodrow, J. E., Seiber, J. N. \& Miller, G. C. Acrylamide release resulting from sunlight irradiation of aqueous polyacrylamide/iron mixtures. J. Agric. Food Chem. 56, 2773-2779 (2008).

86. Nakamiya, K. \& Kinoshita, S. Isolation of Polyacrylamide-degrading Bacteria. J. Ferment. Bioeng. 80, 418-420 (1995).
87. Yu, F., Fu, R., Xie, Y. \& Chen, W. Isolation and characterization of polyacrylamidedegrading bacteria from dewatered sludge. Int. J. Environ. Res. Public Health 12, 4214-4230 (2015).

88. Joshi, S. J. \& Abed, R. M. Biodegradation of polyacrylamide and its derivatives. Environ. Process. 4, 463-476 (2017).

89. Matsuoka, H., Ishimura, F., Takeda, T. \& Hikuma, M. Isolation of polyacrylamidedegrading microorganisms from soil. Biotechnol. Bioprocess Eng. 7, 327-330 (2002).

90. Ma, F., Wei, L., Wang, L. \& Chang, C.-C. Isolation and identification of the sulphate-reducing bacteria strain $\mathrm{H} 1$ and its function for hydrolysed polyacrylamide degradation. Int. J. Biotech. 10, 55-63 (2008).

91. Kay-Shoemake, J. L., Watwood, M. E., Sojka, R. E. \& Lentz, R. D. Polyacrylamide as a substrate for microbial amidase in culture and soil. Soil Biol. Biochem. 30, 1647-1654 (1998).

92. Shanker, R., Ramakrishna, C. \& Seth, P. K. Microbial degradation of acrylamide monomer. Arch. Microbiol. 154, 192-198 (1990).

93. Kay-Shoemake, J. L., Watwood, M. E., Lentz, R. D. \& Sojka, R. E. Polyacrylamide as an organic nitrogen source for soil microorganisms with potential effects on inorganic soil nitrogen in agricultural soil. Soil Biol. Biochem. 30, 1045-1052 (1998).

94. Kjeldsen, P. et al. Present and long-term composition of MSW landfill leachate: a review. Crit. Rev. Environ. Sci. Technol. 32, 297-336 (2002).

95. Chu, C. P. et al. Anaerobic digestion of polyelectrolyte flocculated waste activated sludge. Chemosphere 53, 757-764 (2003).

96. Dai, X. L. F., Yi, J., He, Q. \& Dong, B. Biodegradation of polyacrylamide by anaerobic digestion under mesophilic condition and its performance in actual dewatered sludge system. Bioresour. Technol. 153, 55-61 (2014).

97. Wang, D. et al. Understanding the impact of cationic polyacrylamide on anaerobic digestion of waste activated sludge. Water Res. 130, 281-290 (2018).

98. Zhao, L., Bao, M., Yan, M. \& Lu, J. Kinetics and thermodynamics of biodegradation of hydrolyzed polyacrylamide under anaerobic and aerobic conditions. Bioresour. Technol. 216, 95-10 (2016).

99. United States Environmental Protection Agency. National Primary Drinking Water Regulations Acrylamide (USEPA, Washington, DC, 1995).

100. Touze, S., Guerin, V., Guezennec, A. G., Binet, S. \& Togola, A. Dissemination of acrylamide monomer from polyacrylamide-based flocculant use-sand and gravel quarry case study. Environ. Sci. Pollut. Res. Int. 22, 6423-6430 (2015).

101. Electronic Code of Federal Regulations. Secondary direct food additives permitted in food for human consumption. https://www.ecfr.gov/cgi-bin/text-idx? $\mathrm{SID}=869 \mathrm{e} 33 \mathrm{c} 7 \mathrm{a} 9 \mathrm{fb} 2 \mathrm{e} 86057 \mathrm{a} 37 \mathrm{e} 4504 \mathrm{f0dd} 9 \& \mathrm{mc}=$ true\&node $=\mathrm{pt} 21.3$. 173\&rgn=div5 (1977). (Last accessed 30 Apr 2018).

102. National Resource Conservation Service. Irrigation erosion control (Polyacrylamide). WNTC Interim, 201-201 (NRCS, Washington, DC,1995).

103. Official Journal of the European Communities. Commission Directive 92/39/EEC of 14 May 1992 amending Directive 90/128/EEC relating to plastics materials and articles intended to come into contact with foodstuffs. http://eur-lex.europa.eu/ legal-content/EN/ALL/?uri=CELEX\%3A31992L0039 (European Union, Brussels, Belgium, 1992). (Last accessed 4 Apr 2018).

104. Smith, E. A., Prues, S. L. \& Oehme, F. W. Environmental degradation of polyacrylamides. Ecotoxicol. Environ. Saf. 37, 76-91 (1997).

105. Smith, E. A., Prues, S. L. \& Oehme, F. W. Environmental degradation of polyacrylamides. 1. Effects of artificial environmental conditions: temperature, light, and $\mathrm{pH}$. Ecotoxicol. Environ. Saf. 35, 121-135 (1996).

106. Ver Vers, L. M. Determination of acrylamide monomer in polyacrylamide degradation studies by high-performance liquid chromatography. J. Chromatogr. Sci. 37, 486-494 (1999).

107. Vepsäläinen, M. et al. Investigations of the effects of temperature and initial sample $\mathrm{pH}$ on natural organic matter (NOM) removal with electrocoagulation using response surface method (RSM). Sep. Purif. Technol. 69, 255-261 (2009).

108. Chellam, S. \& Sari, M. A. Aluminum electrocoagulation as pretreatment during microfiltration of surface water containing NOM: A review of fouling, NOM, DBP, and virus control. J. Hazard Mater. 304, 490-501 (2016).

109. Zhong, J., Sun, X. \& Wang, C. Treatment of oily wastewater produced from refinery processes using flocculation and ceramic membrane filtration. Sep. Purif. Technol. 32, 93-98 (2003).

110. Zhang, Y. et al. Treatment of produced water from polymer flooding in oil production by the combined method of hydrolysis acidification-dynamic membrane bioreactor-coagulation process. J. Pet. Sci. Technol. Eng. 74, 14-19 (2010).

111. Zeng, Y., Yang, C., Zhang, J. \& Pu, W. Feasibility investigation of oily wastewater treatment by combination of zinc and PAM in coagulation/flocculation. $J$. Hazard Mater. 147, 991-996 (2007).

112. Zouboulis, A. I. \& Avranas, A. Treatment of oil-in-water emulsions by coagulation and dissolved-air flotation. Colloids Surf. A: Physicochem. Eng. Asp. 172, 153-161 (2000).

113. Zinatizadeh, A. A. et al. Polyacrylamide-induced coagulation process removing suspended solids from palm oil mill effluent. Sep. Sci. Technol. 52, 520-527 (2017). 
114. Gehr, B. R., \& Soponkanaporn, T. Assessing polyelectrolyte behavior by sizeexclusion chromatography. J. Environ. Eng. 116, 343-360 (1990).

115. Yang, G. P., Zhao, X. K., Sun, X. J. \& Lu, X. L. Oxidative degradation of diethyl phthalate by photochemically-enhanced Fenton reaction. J. Hazard Mater. 126, 112-118 (2005).

116. Cheng, P. Chemical and photolytic degradation of polyacrylamides used in potable water treatment, Ph.D. Thesis, University of South Florida (2004).

117. Suzuki, J., Harada, H. \& Suzuki, S. Ozone treatment of water-soluble polymers. V. Ultraviolet irradiation effects on the ozonization of polyacrylamide. J. Appl. Polym. Sci. 24, 999-1006 (1979).

118. Kurenkov, V. F., Hartan, H.-G. \& Lobanov, F. I. Degradation of polyacrylamide and its derivatives in aqueous solutions. Russ. J. Appl. Chem. 75, 1039-1050 (2002).

119. Safarzadeh-Amiri, A., Bolton, J. R. \& Cater, S. R. Ferrioxalate-mediated photodegradation of organic pollutants in contaminated water. Water Res. 31, 787-798 (1997).

120. Lucas, M. S., \& Peres, J. A. Removal of emerging contaminants by Fenton and UV-driven advanced oxidation processes. Water Air Soil Pollut 226, 273 (2015).

121. Fenton, H. J. H. Oxidation of tartaric acid in presence of iron. J. Chem. Soc., Trans. 65, 899-909 (1894).

122. Glaze, W. H. Drinking-water treatment with ozone. Environ. Sci. Technol. 21, 224-230 (1987).

123. Prajapat, A. L. \& Gogate, P. R. Intensified depolymerization of aqueous polyacrylamide solution using combined processes based on hydrodynamic cavitation, ozone, ultraviolet light and hydrogen peroxide. Ultrason. Sonochem. 31, 371-382 (2016).

124. Mallevialle, J., Bruchet, A. \& Fiessinger, F. How safe are organic polymers in water treatment? J. Am. Water Works Assoc. 76, 87-93 (1984).

125. Agency for Toxic Substances and Disease Registry. Toxicological Profile for Chloroform https://www.atsdr.cdc.gov/toxprofiles/tp.asp?id=53\&tid=16 (ATSDR, Atlanta, GA, 1997).

126. Morris, J. The chemistry of aqueous chlorine in relation to water chlorination: Environmental impact and health effects (ed. Jolley R.L.) (Ann Arbor Science Publishers, Michigan, 1975).

127. Bao, M., Chen, Q., Li, Y. \& Jiang, G. Biodegradation of partially hydrolyzed polyacrylamide by bacteria isolated from production water after polymer flooding in an oil field. J. Hazard Mater. 184, 105-110 (2010).

128. Riley, S. M., Oliveira, J. M. S., Regnery, J. \& Cath, T. Y. Hybrid membrane biosystems for sustainable treatment of oil and gas produced water and fracturing flowback water. Sep. Purif. Technol. 171, 297-311 (2016)

129. Freedman, D. E. et al. Biologically active filtration for fracturing flowback and produced water treatment. J. Water Process Eng. 18, 29-40 (2017).

130. Dai, X. et al. Waste-activated sludge fermentation for polyacrylamide biodegradation improved by anaerobic hydrolysis and key microorganisms involved in biological polyacrylamide removal. Sci. Rep. 5, 11675 (2015).

131. He, Y. \& Jiang, Z.-W. Technology review: treating oilfield wastewater. Filtr. Sep. 45, 14-16 (2008).

132. Kasemset, S., Lee, A., Miller, D. J., Freeman, B. D. \& Sharma, M. M. Effect of polydopamine deposition conditions on fouling resistance, physical properties, and permeation properties of reverse osmosis membranes in oil/water separation. J. Membr. Sci. 425, 208-216 (2013).

133. Hickenbottom, K. L., et al. Forward osmosis treatment of drilling mud and fracturing wastewater from oil and gas operations. Desalination 312, 60-66 (2013).

134. Olsson, O., Weichgrebe, D. \& Rosenwinkel, K.-H. Hydraulic fracturing wastewater in Germany: composition, treatment, concerns. Environ. Earth Sci. 70, 3895-3906 (2013).

135. Martinetti, C. R., Childress, A. E. \& Cath, T. Y. High recovery of concentrated RO brines using forward osmosis and membrane distillation. J. Membr. Sci. 331, 31-39 (2009).

136. Xiong, B., Zydney, A. L., \& Kumar, M. Fouling of microfiltration membranes by flowback and produced waters from the Marcellus shale gas play. Water Res. 99, 162-170 (2016).

137. Wang, X., et al. Study of the contribution of the main pollutants in the oilfield polymer-flooding wastewater to the critical flux. Desalination 273, 375-385 (2011).

138. Wang, S., Liu, C. \& Li, Q. Fouling of microfiltration membranes by organic polymer coagulants and flocculants: controlling factors and mechanisms. Water Res. 45, 357-365 (2011).

139. Zhang, H., Zhong, Z. \& Xing, W. Application of ceramic membranes in the treatment of oilfield-produced water: effects of polyacrylamide and inorganic salts. Desalination 309, 84-90 (2013).

140. Bolto, B. \& Gregory, J. Organic polyelectrolytes in water treatment. Water Res. 41 2301-2324 (2007)

141. $\mathrm{Yi}, \mathrm{X}$. S., et al. Factorial design applied to flux decline of anionic polyacrylamide removal from water by modified polyvinylidene fluoride ultrafiltration membranes. Desalination 274, 7-12 (2011).
142. Mimoune, S. \& Amrani, F. Experimental study of metal ions removal from aqu eous solutions by complexation-ultrafiltration. J. Membr. Sci. 298, 92-98 (2007).

143. Hao, X., et al. Influences of partially hydrolyzed polyacrylamide (HPAM) residue on the flocculation behavior of oily wastewater produced from polymer flooding. Sep. Purif. Technol. 62, 199-204 (2008).

144. Lu, D., Zhang, T. \& Ma, J. Ceramic membrane fouling during ultrafiltration of oil/ water emulsions: roles played by stabilization surfactants of oil droplets. Environ. Sci. Technol. 49, 4235-4244 (2015).

145. Lande, S. S., Bosch, S. J. \& Howard, P. H. Degradation and leaching of acrylamide in soil. J. Environ. Qual. 8, 133-137 (1979).

146. Wallace, A., Wallace, G. A. \& Abouzamzam, A. M. Effects of excess levels of a polymer as a soil conditioner on yields and mineral nutrition of plants. Soil Sci. 141, 377-380 (1986).

147. McCollister, D., Hake, C., Sadek, S. \& Rowe, V. Toxicologic investigations of polyacrylamides. Toxicol. Appl. Pharmacol. 7, 639-651 (1965).

148. LoPachin, R. M. The changing view of acrylamide neurotoxicity. Neurotoxicology 25, 617-630 (2004).

149. Tanii, H. \& Hashimoto, K. Studies on in vitro metabolism of acrylamide and related compounds. Arch. Toxicol. 48, 157-166 (1981).

150. USEPA. Toxicological Review of Acrylamide CAS No 79-06-1. Report No. EPA/635/ R-07/009A; NCEA-S-1666 (U.S. Environmental Protection Agency, Washington, DC, 2007). (Last accessed 4 Apr 2018).

151. U.S. Department of Health and Human Services. Occupational Safety and Health Guideline for Acrylamide [Fact Sheet]. http://www.cdc.gov/niosh/docs/81-123/ pdfs/0012-rev.pdf (1992). (Last accessed 4 Apr 2018).

152. Bodner, K. M., et al. Chronic toxicity and oncogenicity study on acrylamide incorporated in the drinking water of Fischer 344 rats. Toxicol. Appl. Pharmacol. 85, 154-168 (1986).

153. Hazardous Substances Data Bank. Acrylamide, CASRN: 79-06-1. U.S. National Library of Medicine. https://toxnet.nlm.nih.gov/cgi-bin/sis/search2/f?./temp/ d4ten6:1 (2009) (Last accessed 4 Apr 2018).

154. Labahn, S. K., Fisher, J. C., Robleto, E. A., Young, M. H., \& Moser, D. P. Microbially mediated aerobic and anaerobic degradation of acrylamide in a western United States irrigation canal. J. Environ. Qual 39, 1563-1569 (2010).

155. Shukor, M.Y. et al. Isolation and characterization of an acrylamide-degrading Bacillus cereus. J. Environ. Biol. 30, 57-64 (2009).

156. Brown, L., Bancroft, K. \& Rhead, M. Laboratory studies on the adsorption of acrylamide monomer by sludge, sediments, clays, peat and synthetic resins. Water Res. 14, 779-781 (1980).

157. Brown, L., Rhead, M. M., Hill, D. \& Bancroft, K. C. C. Qualitative and quantitative studies on the in situ adsorption, degradation and toxicity of acrylamide by the spiking of the waters of two sewage works and a river. Water Res. 16, 579-591 (1982).

158. Brown, L., Rhead, M. M., Bancroft, K. C. C. \& Allen, N. Model studies of the degradation of acrylamide monomer. Water Res. 14, 775-778 (1980).

159. Rassenfoss, S. From flowback to fracturing: water recycling grows in the Marcellus shale. (Society of Petroleum Engineers, Richardson, TX, 2011).

160. Woodroof, R. A. Jr \& Anderson, R. W. Synthetic polymer friction reducers can cause formation damage. In SPE Annual Fall Technical Conference and Exhibition. (Society of Petroleum Engineers, Richardson, TX, 1977).

161. Gall, B. L., Sattler, A. R., Maloney, D. R. \& Raible, C. J. Permeability damage to natural fractures caused by fracturing fluid polymers. (Society of Petroleum Engineers, Richardson, TX, 1988).

162. Mirzaei Paiaman, A., Moghadasi, J. \& Masihi, M. Formation damage through aqueous phase trapping in gas reservoirs. In SPE Deep Gas Conference and Exhibition (Society of Petroleum Engineers, Richardson, TX, 2010).

163. Yongrui, $P$., et al. Treatment of partially hydrolyzed polyacrylamide wastewater by combined Fenton oxidation and anaerobic biological processes. Chem. Eng. J. 273, 1-6 (2015)

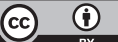

Open Access This article is licensed under a Creative Commons Attribution 4.0 International License, which permits use, sharing, adaptation, distribution and reproduction in any medium or format, as long as you give appropriate credit to the original author(s) and the source, provide a link to the Creative Commons license, and indicate if changes were made. The images or other third party material in this article are included in the article's Creative Commons license, unless indicated otherwise in a credit line to the material. If material is not included in the article's Creative Commons license and your intended use is not permitted by statutory regulation or exceeds the permitted use, you will need to obtain permission directly from the copyright holder. To view a copy of this license, visit http://creativecommons. org/licenses/by/4.0/.

(c) The Author(s) 2018 